\title{
Estimating large woody debris volume and distribution floated and accumulated in reservoir using aerial photographs
}

\author{
Waku Suzuki ${ }^{1}$, Sohei Kobayashi ${ }^{2, *}$, Sameh Kantoush ${ }^{2}$, Yasuhiro Takemon ${ }^{2}$, and \\ Tetsuya Sumi $^{2}$ \\ ${ }^{1}$ Faculty of Engineering, Kyoto University, Nishikyo-ku, Kyoto 615-8530, Japan \\ ${ }^{2}$ Disaster Prevention Research Institute, Kyoto University, Uji, Kyoto 611-0011, Japan
}

\begin{abstract}
Large woody debris (LWD) could increase the risk of flooding in the event of heavy rainfall, and fast estimation of the accumulated LWD is crucial for river basin management. We develop a method to automatically detect LWD floating in reservoirs using airborne images, and estimated the total volume of LWD accumulated in a reservoir during a severe flood event in northern Kyushu, Japan, early July 2017. The LWD was successfully extracted from the images based on colour and brightness by using ImageJ. The total volume of the accumulated LWD estimated from images was similar to the LWD volume actually removed from the reservoir by the end of October. Most LWD pieces were concentrated in the upstream-side of the reservoir, and a longitudinal variation in density and length of LWD pieces was also evident.
\end{abstract}

\section{Introduction}

Monitoring and management of large woody debris (LWD) in river channels, known as driftwood, have attracted attention due to heavy rainfall and extreme floods that generate a massive volume of LWD into river systems. LWD causes disasters through its accumulation around bridges, houses and water resource facilities $[1,2]$. An accurate and fast assessment of LWD distribution, sizes and volumes are important to predict the associated risks and to plan appropriate mitigation measures during or immediately after flood events. Although many studies have demonstrated the spatial distribution of LWD in the channel [3, 4], there is no effective method to quantify LWD that is transported or accumulated by a flood event. River managers in Japan usually estimate the volume of LWD produced during each major flood event based on rough calculations of tree biomass data in hillslopes and channel banks and the area of erosion of such places. The volume of LWD accumulation in dams can be measured by a removal work, though it usually takes more than a few to several months. Data of such LWD volume has been statistically analysed to understand regional variation in the amount of transported LWD in Japanese rivers [5].

Recently, an extreme rainfall hit the northern Kyushu of Japan in early July 2017, and induced occurrence of many debris flows and severe floods that damaged infrastructures and

*

Corresponding author: sohei.kobayashi@gmail.com 
took almost 40 lives. A massive volume of LWD was transported towards various locations inside and outside the river channels. The accumulated LWD destroyed bridges and houses, and induced inundation by impeding flow. A post-event survey reported that damages and inundation were less evident in a watershed with a dam (Terauchi Dam) despite the extreme rainfall. Flood disaster was likely to be mitigated by the dam that stored $90 \%$ of the peak flow discharge and trapped all transported LWD from the upstream watershed.

The river managers conducted a rough estimation of LWD quantities from the mountains based on wood biomass of each forest type including floodplain areas, and area of erosion determined by aerial photos. However, a part of LWD pieces from mountains was trapped in the upstream channel and did not reach to the reservoir. A removal of LWD from the reservoir was conducted after few months as part of river clean-up and improvement measures in a post disaster project. Prior to the removal, river managers are often required to estimate the volume of LWD in reservoirs with certain accuracy. But, the actual volume of LWD is largely unknown until the completion of the removal. Most LWD pieces entered in reservoirs are floated and visible soon after floods. Recently, UAV (unmanned aerial vehicle) is practically used in the inspection and maintenance of reservoirs after floods. According to the resolution of the images taken by UAV (higher than $0.01-0.02 \mathrm{~mm} / \mathrm{pixel}$ ), individual pieces of LWD can be identified. To our knowledge, few studies have examined the spatial distribution of LWD within reservoirs and estimated the volume of LWD from images. On the other hand, various studies focused on image analysis in river channels [6].

The main objective of this paper was to develop a method to easily evaluate, and analyse the sizes and quantities of LWD accumulated in reservoirs. The measured volume of LWD from images was calibrated and compared with the actual volume of LWD quantified by a removal project.

\section{Sites and methods}

\subsection{Target dam and storm event}

The Sata River is a tributary of the Chikugo River, which is known as one of the three major disastrous rivers in Japan, in Fukuoka Prefecture, north Kyushu Island (Fig. 1). The Terauchi Dam in the Sata River is a rockfill with height of $83.0 \mathrm{~m}$ and multipurpose with total storage capacity of $18 \times 10^{6} \mathrm{~m}^{3}$ mainly for flood mitigation, irrigation, drinking water, and has upstream watershed of $51 \mathrm{~km}^{2}$. It was constructed in 1978, and has been owned by Japan Water Agency (JWA).

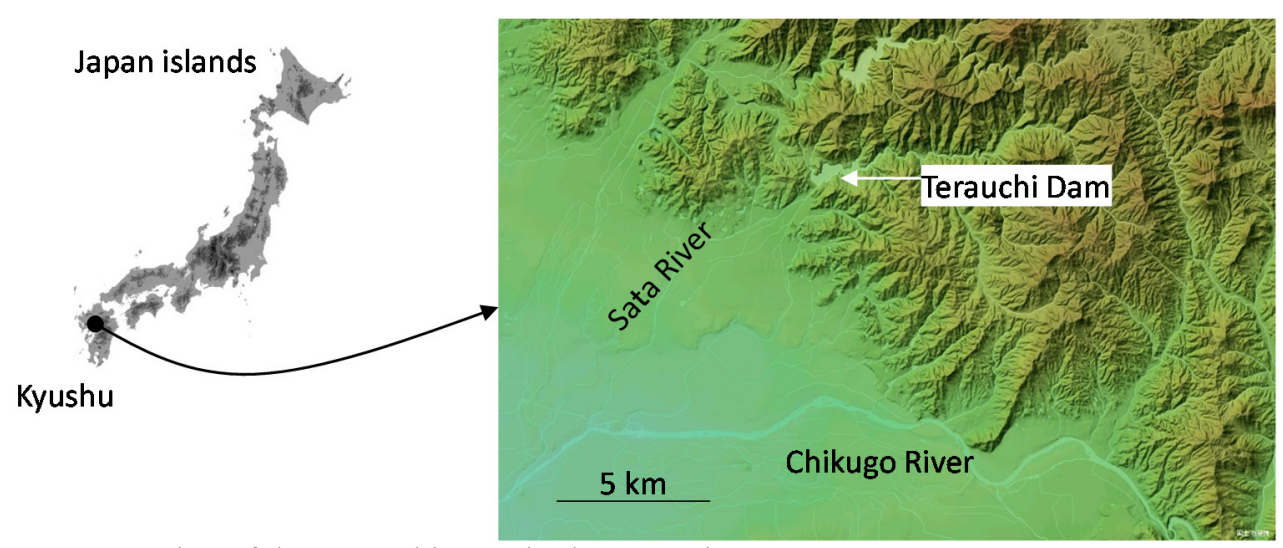

Fig. 1. Location of the Terauchi Dam in the Sata River. 
The upstream raingauge (Hashidate station) recorded the rainfall intensity of $106 \mathrm{~mm} / \mathrm{hr}$ between $15 \mathrm{~h} 00$ and $16 \mathrm{~h} 00$ on the $5^{\text {th }}$ of July 2017 , and $412 \mathrm{~mm}$ for the total event from $7 \mathrm{~h} 00$ of $5^{\text {th }}$ to $4 \mathrm{~h} 00$ of $6^{\text {th }}$ July. The peak inflow discharge was $888 \mathrm{~m}^{3} / \mathrm{s}$, which was the largest since 1978. The Ministry of Land, Infrastructure, Transport and Tourisms (MLIT) estimated the volume of recruited LWD from mountain forests and valley floodplains based on forest type, wood biomass, and eroded area as $19,000 \mathrm{~m}^{3}$ in total with $57 \%$ from hillslopes and $42 \%$ from floodplains in the upstream catchment of the Terauchi dam.

A large volume of LWD was accumulated in the reservoir of the Terauchi Dam (Fig. 2). Part of LWD from upstream hillslopes and floodplains was trapped in the upstream channel of the dam (deposited just lower side of landslides, at confluences, and upstream of vegetation and bridges). In the reservoir, most of LWD was trapped in the upper section and did not reach to the water intakes or spillway gates of the dam (Fig. 2). Most of the accumulated LWD was removed from the reservoir by the end of October 2017 and the total volume was quantified to be $8,400 \mathrm{~m}^{3}$, which was less than half of the volume estimated by MLIT.
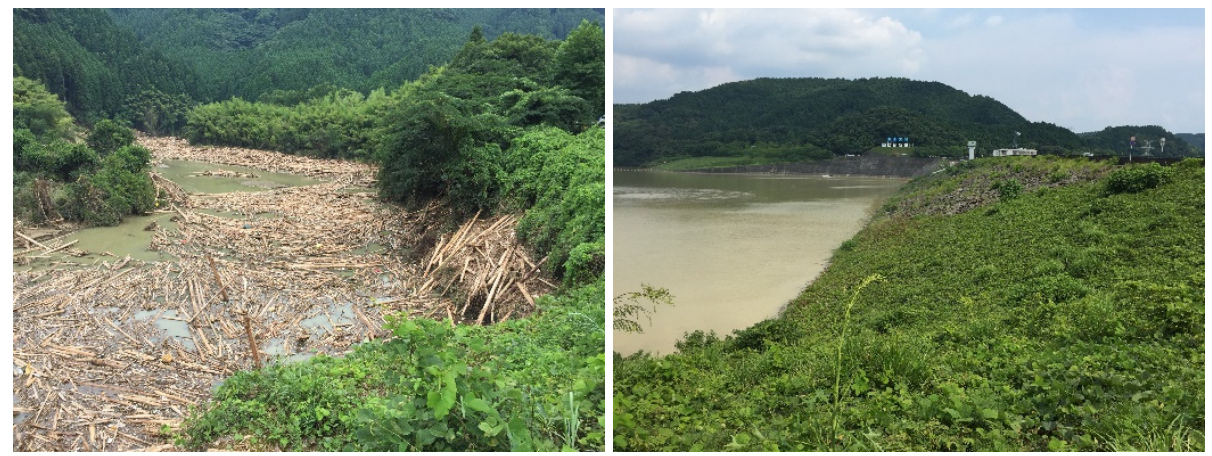

Fig. 2. Photos in the upstream side (left) and front side (right) of the Terauchi Dam.

\subsection{Aerial photos by UAV}

Photos were taken using UAV (flight height of $>100 \mathrm{~m}$ ) on $19^{\text {th }}$ of July (almost 2 weeks after the flood event) inside the reservoir area and up to a few hundred meters upstream of the main river by JWA. More than 150 images (resolution: 4,000 $\times 3,000$ pixels) were taken with camera perpendicular to the water surface. The scale in the images were determined as 40 $\mathrm{mm} /$ pixel in the upper region and $28 \mathrm{~mm} / \mathrm{pixel}$ in the lower region based on floating artificial materials with known sizes such as steel drums (Fig. 3).
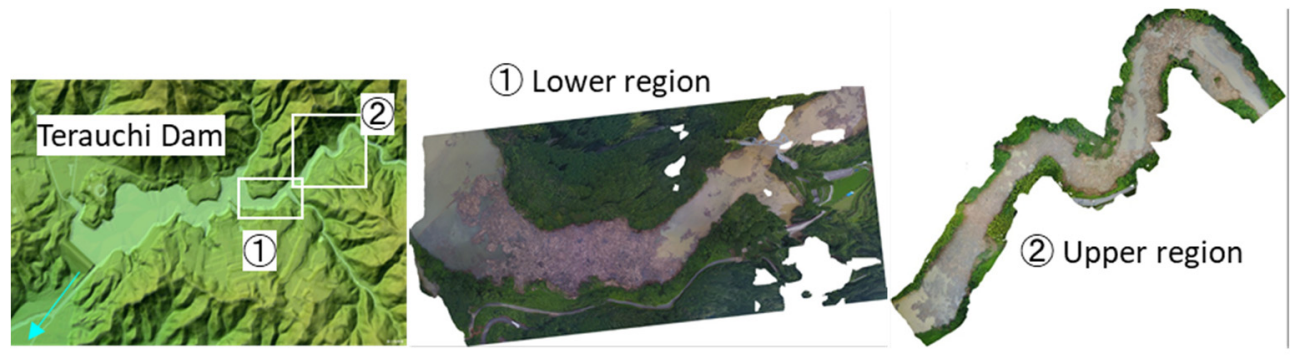

Fig. 3. Analysed region in the reservoir (LWD is visible in brown in both photos). 


\subsection{Image analysis by ImageJ}

\subsubsection{Automatic extraction of woody pieces}

In order to develop a method to easily estimate the volume and size of LWD pieces, a public domain software, Image J [7], was used to automatically extract woody pieces from images. After intensive trials of using variable pigments for detecting woody pieces, we recognized that woody pieces have red pigments in many of the images. Using a command of "colour threshold", woody pieces were well-extracted when we used 30 in Hue, which is a gradation of colour along a single axis, and 140-170 in brightness in Hue Saturation and Brightness (HSB) components (Fig. 4). Woody pieces were unable to extract accurately by the hue component in some images. For such cases, images were converted to 8-bit grayscale, and brightness was use to extract woody pieces. We finally used brightness of 150 for extraction. Because, in the grayscale, a large area of water surface was sometimes extracted together with LWD, we have to remove such area before the analysis.

Multiple woody pieces were sometimes overlapped and they were identified as one large piece. Because we used size (long and short axes length) of individual pieces to estimate volume of LWD, such miss-identification leads overestimation of the volume. To solve this issue, we used command of "watershed segmentation", in which a single particle is divided by an algorism of finding ridge based on the distance from the edge at each pixel. The watershed segmentation tended to over-separate single LWD into smaller pieces (Fig. 5). Also, it tended to separate into shorter pieces rather than thinner pieces due to the segmentation algorism (Fig. 5).

Size of each pieces was measured using a command of "measure particles", in which long and short axes of each particles are calculated. We assumed a cylindrical shape of each LWD, and used long axis as length and short axis as diameter of LWD. The watershed segmentation tended to separate single LWD into several shorter pieces as mentioned. If the size of shorter axis (LWD diameter component) is unchanged, the total volume of the several pieces is supposed to be almost the same with the volume of the original piece (Fig. 5). However, we noticed that both long and short axis changed for part of the pieces, which leads to underestimate the total volume.
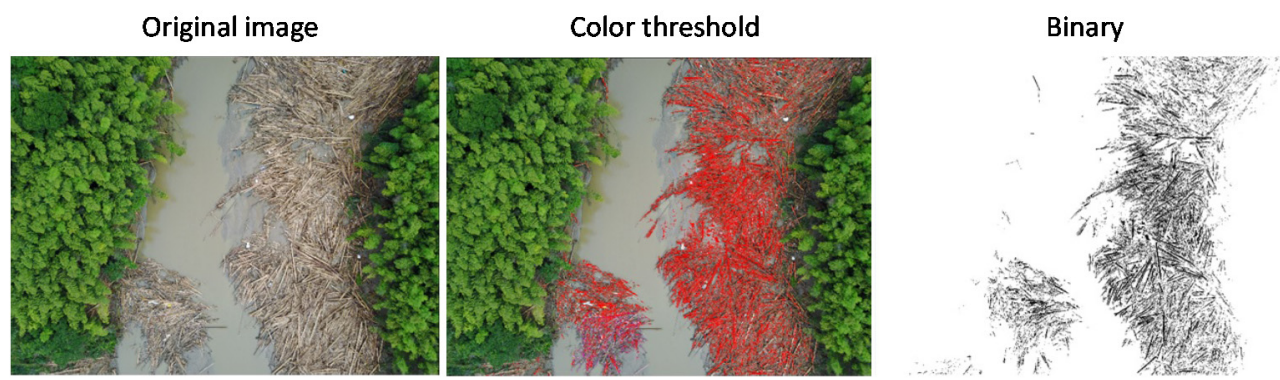

Fig. 4. An example of extracting LWD in images using ImageJ. 

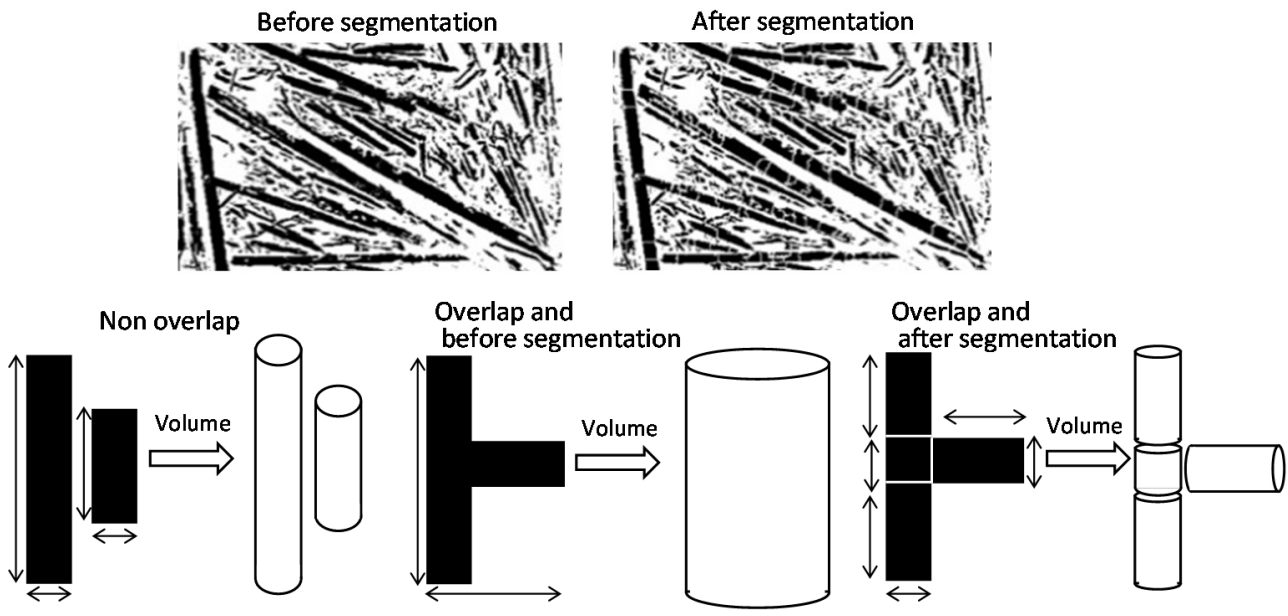

Fig. 5. An example of watershed segmentation of overlapped pieces and size analysis.

\subsubsection{Manual extraction of woody pieces}

Underestimation of the volume by the automatic extraction methods was inevitable because of limitations to detect all LWD pieces by colour and brightness as well as by the segmentation process as mentioned. To calibrate the volume of LWD esitamated by the automatic method, we also extracted LWD manually for 4 images, which varied in density of LWD, in each of the upper and lower region. Lines of long and short axes of each LWD in images were drawn by eyes and hands and the length of each line was measured using ImageJ. We assumed a cylindrical shape to estimate volume as in the automatic method.

\section{Results}

\subsection{Size distribution of accumulated LWD}

All of the LWD extracted by the manual method was combined for the upper and lower region of the reservoir to understand size distribution of LWD and contribution of different size classes to the total volume of LWD. Size classes were $0.5 \mathrm{~m}$ interval for LWD length, and $0.05 \mathrm{~m}$ interval for LWD diameter. The frequency distribution in LWD length was peaked at 1.5-2 m (median: $2.2 \mathrm{~m}$, max.: $16.3 \mathrm{~m}$ ) in the upper region and 1-1.5 m (median: 1.7, max.:10.7) in the lower region, suggesting that LWD pieces were longer in the upper region. Contribution to the total volume was peaked 2.0-3.0 $\mathrm{m}$ in the upper, and 1.0-2.0 $\mathrm{m}$ in the lower region (Fig. 6). Because of the segmentation process, $96.3 \%$ of the pieces were less than $1 \mathrm{~m}$ in length for the automatic method.

Contribution of different diameter classes to the total volume was compared between the manual and automatic methods. The contribution was peaked at $0.20-0.35 \mathrm{~m}$ for the manual method, while it was $0.15-0.30 \mathrm{~m}$ for the automatic method, suggesting that LWD pieces detected by the automatic method was smaller than that by the manual method due to a limitation in extracting whole pieces by colour and brightness, and the segmentation process. Despite such limitations and errors, larger pieces contributed more in the upper than lower region for the automatic method as well as the manual method. 


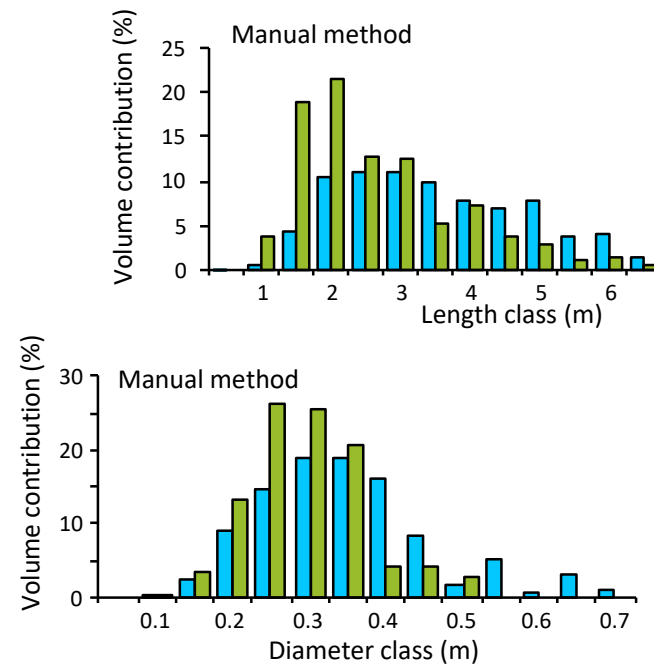

Upper $\square$ Lower

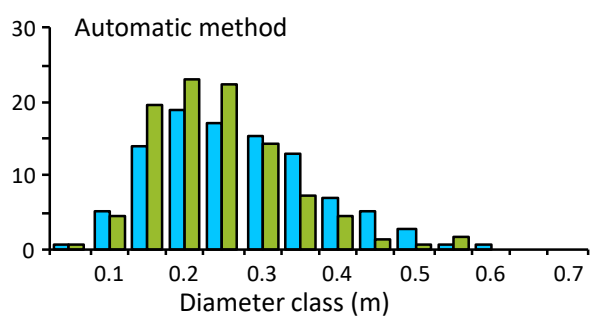

Fig. 6. Contribution of different size classes to the total volume of LWD in the regions.

\subsection{Total volume of accumulated LWD}

Volumes of extracted LWD were summed for each image. Relationship between the automatic and manual method was examined using the corresponding images. In the upper region, in which the volume by manual method varied from $0.111 \mathrm{~m}^{3} / \mathrm{m}^{2}$ to $0.182 \mathrm{~m}^{3} / \mathrm{m}^{2}$, the volume of the two methods was well correlated with correlation coefficient $R$ of 0.98 (Fig. 7). While in the lower region, the volume by manual method varied from $0.067 \mathrm{~m}^{3} / \mathrm{m}^{2}$ to 0.1 $\mathrm{m}^{3} / \mathrm{m}^{2}$, and the volume of the two method were also correlated $(R: 0.90)$. When two regions were pooled, $R$ was 0.95 .

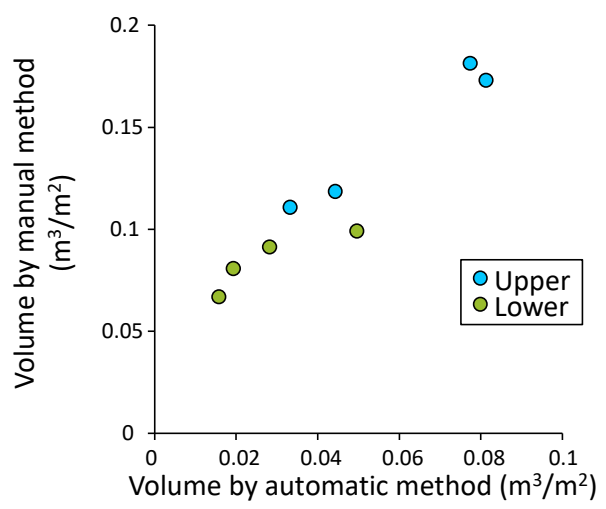

Fig. 7. Relationship in estimated LWD volume between manual and automatic methods.

To calibrate the volume of LWD by the automatic method, the volume of LWD by the manual method ( $\left.V_{\text {manual }}\right)$ was linearly regressed by the volume of automatic method ( $\left.V_{\text {automatic }}\right)$ for each region separately,

$$
V_{\text {manual }}=1.4927 V_{\text {automatic }}+0.0584
$$




$$
V_{\text {manual }}=0.8141 V_{\text {automatic }}+0.0623
$$

with equation (1) for the upper and equation (2) for the lower region. After the correction, the volume of LWD was estimated for each image, and then summed for each region (upper: $5,630 \mathrm{~m}^{3}$, lower: $\left.2,107 \mathrm{~m}^{3}\right)$, and for the whole reservoir $\left(7,737 \mathrm{~m}^{3}\right)$.

\subsection{Longitudinal variation in LWD density in the reservoir}

The reservoir was further divided finely using $10-\mathrm{m}$ grid to examine spatial variation in LWD density (in terms of volume per unit water surface area). Fifty grids with identical area (100 $\mathrm{m}^{2}$ ) were selected along the thalweg. The density of LWD varied largely in the upper section (distance 0 to $1000 \mathrm{~m}$ ) but tended to steadily decrease in the downstream direction (Fig. 8). LWD was distributed sparsely in a middle section between $1000 \mathrm{~m}$ to $1400 \mathrm{~m}$ (analysis was skipped for this section). In the lower section (1400 $\mathrm{m}$ to $1800 \mathrm{~m}$ ), the density of LWD was steadily low.

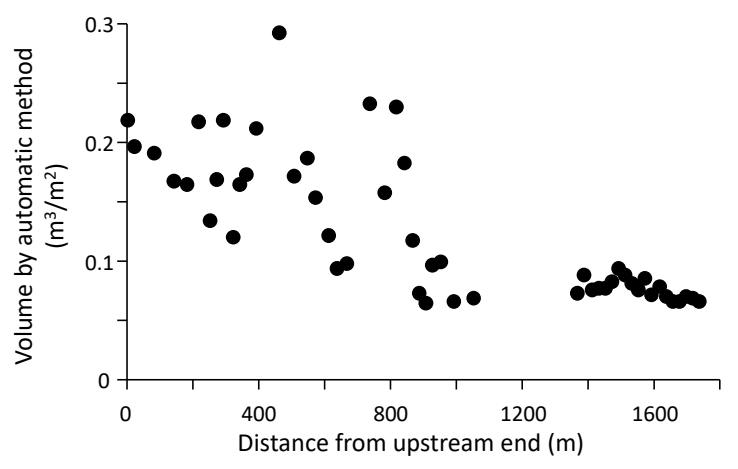

Fig. 8. Longitudinal profile of LWD volume estimated by automatic method.

\section{Discussion and Conclusion}

The estimated volume of LWD in the reservoir from the images $\left(7,737 \mathrm{~m}^{3}\right)$ was close to the volume of LWD actually removed from the reservoir $\left(8,400 \mathrm{~m}^{3}\right)$. Underestimation by the image analysis is reasonable because some LWD pieces were overlapped each other and not all pieces floated horizontally on the water surface. The volume of LWD recruited from hillslopes and floodplains estimated by MLIT was about $19,000 \mathrm{~m}^{3}$. There were many accumulations of LWD in the upstream channel (personal observation in the field and in available aerial photos). Therefore, less than half (in volume) of produced LWD reached the reservoir. Our estimation method is useful tool for a first hand estimation of LWD accumulated in the reservoir, in which many LWD pieces are floated on the water surface. A calibration of the LWD volume between automatic and manual extraction methods would be needed to apply to other reservoirs. The present method is difficult to use for the accumulation of LWD in the channel, because the pieces are often overlapped and stayed in variable angles.

Size (e.g., length, diameter) of individual LWD pieces can also be evaluated by image analysis. In this study, in order to remove an effect of overlapping between different pieces, we adopted watershed segmentation before the automatic analysis of the volume. Consequently, each LWD piece was cut into several shorter pieces, which made impossible to determine length of actual individual pieces. We could still evaluate the total volume or 
length of each diameter class, which may be enough for the evaluation of relative difference in size among different locations in the reservoir.

We showed that most of LWD was accumulated in the upstream portion of the reservoir, and did not reach the front-side of the reservoir. Within the upstream portion, LWD was much densely accumulated in the upper than the lower side. LWD was also longer in the upper than the lower. LWD is often reported to drift and accumulate at the front of the reservoir where intake/gates are located $[1,2]$. Plunge point of density current, which usually locates in the upper side of a reservoir, is also known to accumulate floating debris [8]. However, the accumulation of LWD in this study occurred further upstream from the plunge point, where the water depth often changes sharply. The valley channel characteristics such as water depth, width, and sinuosity might have affected the distribution of LWD. Further studies are needed to clarify the processes of LWD accumulation occurred in the study reservoir.

In conclusion, we developed a method to automatically detect LWD pieces floating on the water surface of reservoir using airborne images taken by UAV, and estimated the total volume of LWD accumulated in the Terauchi Dam during a severe rainfall and flood event in July 2017. Because our estimation was similar to the volume of LWD actually removed from the reservoir, the method is useful for a quick estimation. Further examinations using images from different reservoirs are needed to validate our method. We also revealed a unique spatial distribution of LWD in the reservoir (i.e., density increased in the upstream direction), and the process of such accumulation is still unknown.

We thank employees of the Terauchi Dam, JWA for giving us photos by UAV and other various information useful for the analysis.

\section{References}

1. C. Ubing, S. Monahan, S. Kimbrel, Science and Technology Program (Final Report), Research and Development Office, Bureau of Reclamation, U.S. Department of the Interior (2016)

2. N. Wallerstein, C. Thorne, S. Abt, Contract Report CHL-97-4, U.S. Army Corps and Engineer Waterways Experiment Station (1997)

3. T. B. Abbe, D. R. Montgomery, Regulated Rivers Research Management 12: 201-221 (1996)

4. R. E. Bilby, P. A. Bisson, In River Ecology and Management (edn R. J. Naiman, R. E. Bilby), Springer-Verlag New York: 324-346 (1998)

5. J. Seo, F. Nakamura, D. Nakano, H. Ichiyanagi, K. W. Chun, Water Resources Research 44: W04428 (2008)

6. J. J. Richardson, L. M. Moskal, Remote Sensing 8: 778

7. C. A. Schneider, W. S. Rasband, K. W. Eliceiri, Nature methods 9: 671-675 (2012)

8. G. L. Morris, J. Fan, Reservoir Sedimentation Handbook: Design and Management of Dams, Reservoirs, and Watersheds for Sustainable Use, McGraw-Hill Book Co., New York (1998) 